cooperation of the various railway companies, every intelligent person in the district was made aware of the impending danger in ample time to make such preparations as they were able.

The floods of 1903 owed their inception to a series of heavy rainfalls caused by a succession of storms of the south-western type, the best rain-producing quarter, coming on the top of the water derived from the melting of the snow on the mountains in the upper reaches.

In the February flood in the lower Mississippi the water rose in one long swell from Cairo to the Gulf of Mexico from 17.5 feet on the gauge on January 28 , passing the danger point of 45 feet thirty-nine days later, and $50^{\frac{1}{2}}$ feet, or $5^{\frac{1}{2}}$ feet above the top of the banks, eight days afterwards. It remained above the danger line for another twelve days, and then began to fall. It will thus be seen that the water in the river during the flood rose 33 feet.

Although excessive rainfall was the original cause of these floods, the effect was greatly increased by works that had been carried out for the improvement of the river and for providing means of inland transport, necessitating the frequent crossing of the river by railway bridges. Formerly a certain amount of relief to the floods was afforded by the water flowing through the numerous crevasses or breaches of the banks that occurred, but during recent years the banks have been systematically raised and strengthened. For example, in the St. Francis system the levees have been extended and raised 2 feet over a length of 173 miles, and the area originally subject to being submerged reduced 4000 square miles. The same operations have been carried on in other districts, so that the flooded area which previous to 1897 extended over 30,000 square miles in 1903 barely reached 7ooo square miles. The fight against this flood was also the most extensive and persistent ever attempted in the history of levee engineering. When a breach was likely to occur all the help and material available was concentrated at the point of greatest weakness. At one place a force of more than 1000 men was employed both day and night, in spite of which the bank gave way for more than a mile.

At another part of the river, about 36 miles below New Orleans, a crevasse occurred at a place where the river is ro feet deep. The bank was all washed away, and where it formerly stood a hole was scoured out 60 feet deep. Owing to the precautions taken, due to the warnings of the Weather Bureau, provision had been made to meet such a catastrophe, and workmen were at once concentrated on the spot, and trainloads of material which had been provided in readiness for such an emergency were brought to the place. By this means the breach was successfully closed, and the flooding of some of the finest sugar plantations in Louisiana averted.

Other causes that contributed to the greater rise of the flood were the numerous railway bridges that had been carried across the river without leaving sufficient waterway for floods. In one place, where the natural width of the river is 900 feet, the waterway had been contracted to 400 feet by a railway bridge, the velocity of the water through which rose to twelve miles an hour.

Encroachments by reclamation have also materially interfered with the free flow of the river, the original width of the channel in some places having been re-
duced one-half.

The report of these floods contains numerous illustrations. which give a very graphic idea of the ruin caused in the flooded areas, and also of the works carried on in repairing the levees. There is also a map of the watershed of the Mississippi and of the flooded areas, and of the rainfall in the different districts.

Two other volumes issued by the Geological Department relate to the floods of the river Passaic in 1902 and 1903, when the loss to the inhabitants of the district was estimated for the two floods at about 3 million pounds. These two volumes also contain numerous very telling illustrations of the flooded areas and of the damage done to houses and factories. ${ }^{1}$

\section{WHAT IS BRANDY?}

THIS question, which a few months ago greatly exercised analytical chemists in this country in consequence of the action of certain local authorities under the Sale of Food and Drugs Acts, has recently engaged the attention of the Technical Committee of Enology, instituted by the French Minister of Commerce by decree of March 22, 1904, and the committee have adopted the conclusions of M. Rocques, the reporter of the subcommittee charged with the consideration of the matter, whose report is published in extenso in the Moniteur Officiel du Commerce of June 30 . In view of the importance of the subject, it may be desirable to give a short summary of the facts and arguments which led the technical committee to adopt the conclusions of the special subcommittee.

In the first place the committee, for reasons which it is unnecessary to explain, object to the term coefficient of impurities, hitherto employed by French chemists, in conformity with a decree of the Minister of Commerce of May 26, I903, to designate the aggregate proportion of the substances other than ethylic alcohol in brandy, and prefer to denote it by the term coefficient non-alcohol, or more simply non-alcohol, by which is to be understood the sum of the different volatile substances, other than ethylic alcohol, expressed in grams per hectolitre of absolute alcohol. These substances are the acids, aldehydes, ethers, the alcohols higher in the homologous series than ethyl alcohol, and the furfurol.

The causes which influence this coefficient are many, but in the main they may be said to depend upon (I) the nature of the wine, (2) the method of distillation, and (3) age.

As regards the first cause, it is found that the proportion, as well as the character, of the volatile matters vary according to the origin of the wine, the conditions under which its fermentation has been effected, the manner in which it has been kept, \&c. The proportion of acids and ethers is considerably augmented if the wine becomes sour, and, speaking generally, the proportion of aldehydes is higher in white than in red wines.

But it is mainly in the method of distillation that we are to seek for the cause of the wide variations in this coefficient. This is readily understood if we examine the manner in which the various substances, which together constitute non-alcohol, behave during distillation. It is known that these substances pass over in very different proportion in the course of the distil. lation. Thus the aldehyde and the more volatile ethers are found mainly in the first runnings (produits de tête), whereas the taillings (produits de queue) contain in largest quantity the higher alcohols and the furfurol.

The separation of these various products-the produits de tête, the alcohol itself (de coeur), and the produits de queue-is effected in a manner more or less complete, depending upon the apparatus employed. In the larger distilleries this apparatus is of a very high order of perfection. But without further labour-

1 The Passaic Flood of 1902 , Water Supply and Irrigation Paper No. 88, and of 1903 , Paper 92. (Washington: Government Printing Office. NO. I827, VOL. 7I] 
ing this point, it is obvious that the aggregate amount and relative proportion of these products must depend very largely upon the means made use of, and hence perfectly genuine brandies must necessarily show wide differences in the coefficient non-alcohol.

In addition, it must be remembered that in the manufacture of brandy from wines of repute, the elimination of the substances constituting non-alcohol must be made with the greatest circumspection, since it is upon their bouquet that the value of these brandies depends, and this bouquet resides wholly in the nonalcohol.

On the other hand, if the brandy is being made from damaged wine the rectification must be most carefully conducted, and may have to be pushed to a point that the alcohol is obtained almost pure, that is to say, almost free from non-alcohol.

As regards the influence of age, it is observed that in those brandies which are found to improve on keeping there is an increase in non-alcohol due (I) to the formation of products of oxidation (acids and aldehydes), and (2) to concentration due to a loss of alcohol and water.

Brandies may be classified in the following manner :-

(1) The brandies of the two Charentes, which are habitually designated by the name of Cognac.

(2) The brandies of Armagnac.

(3) The brandies de vin du Midi and of Algeria (trois-six de Montpellier, \&c.).

(4) Marc brandies.

The brandies of the Charentes are obtained by distillation of the wines of the district, and as the reputation of these brandies depends upon their bouquet they are submitted to a slight rectification only in order to preserve that bouquet.

The same may be said of the Armagnac brandies.

As to brandies made in other viticultural regions, and in particular in the middle of France, their nature is much more variable. These brandies require to be rectified in a manner, more or less complete, depending upon the nature of the wine or of the marc from which they are derived, and varying, too, with the quality of the brandy it is desired to produce. Certain wines require, in fact, to be most carefully rectified in order to produce merchantable brandy. Marc brandy is made in all viticultural regions, and that of Burgundy enjoys a special reputation.

As regards the value of the coefficient in different brandies, it is found that in those of Charente and Armagnac the coefficient is very high. Thus, as minima, a brandy of Clunis (1879, good, but not guaranteed) gave 259 (Girard and Cuniasse). A Cognac of 1892 gave 287 (Rocques). As maxima may be cited a Bois brandy of I8I7, which gave II74 (Lusson). This last number is exceptionally high. It may be said that, ordinarily, the value of the coefficient in Cognacs and fine champagne ranges between 275 and 450 .

But little analytical evidence has been published respecting the Armagnac brandies, but, such as it is, it indicates that the coefficients in their case are less than are generally found in Cognacs.

The brandies obtained from the wines of the Midi and Algeria show much wider variations, ranging from 25 to 500 .

Marc brandies have almost invariably a high coefficient. The numbers range from 555 to 1487 , and it is interesting to note that the aldehydes frequently form a large proportion of the whole. Thus a Burgundy marc brandy was found to contain as much as $5^{\text {I9 }}$ of aldehyde, and one from the Midi as high as 730 of aldehyde.

$$
\text { NO. I } 827 \text {, VOL. } 7 \mathrm{I}]
$$

The question whether it is possible to fix minimum and maximum limits to this coefficient naturally received much consideration from the committee. The fixation of these presents a certain interest, and that from two different points of view. The fixation of a minimum limit has interest for the analyst, as guiding him in his inference as to the genuineness of the brandy or as to the amount of "silent" spirit with which it may have been mixed. The fixation of a maximum limit has an interest from the hygienic point of view, since it may become necessary if regulations are to be established in this sense.

The committee, however, are unable to recommend that any such limits should be fixed, owing mainly to the extremely variable character of brandy. Even in the case of brandies of a definite character, as, for example, Cognac, the non-alcohol coefficient is not the only element of value, and any conclusions as to character cannot be based solely upon it. Regard must be had to the proportions of the different volatile substances and their relations among themselves. Expert tasting (dégustation) must be considered as an indispensable complement of chemical analysis.

The hygienic point of view, involving the fixation of a maximum value for the non-alcohol coefficient, was brought to the notice of the International Congress of Chemistry in Paris in 1900, but the problem, as then stated, received no definite solution. To base conclusions on the value of the coefficient alone, with no regard to the factors which it comprises, seems illogical. For example, the acids, and in particular acetic acid, frequently make up a large proportion of this value, but it cannot be contended that these substances, at least in the proportion in which they are present in brandy, have any detrimental influence. Far more important are the aldehydes, ethers, the higher alcohols, and furfurol.

As regards the higher alcohols, the attempt has been made to establish a higher limit. Thus in Belgium, by a Royal decree of December 3I, 1902, the sale is prohibited of spirituous liquors containing more than I gram of the higher alcohols and essences per litre of absolute alcohol when these liquors have an alcoholic content higher than $90^{\circ}$, and 3 grams when the alcoholic richness does not exceed $90^{\circ}$.

The committee remark that the effect of this regulation would be to exclude some of the most famous, and notably the oldest, brandies of the Charente, many of which exceed the maximum Belgian limit, which, expressed as a non-alcohol coefficient, is 300 . Thus :-

$\begin{array}{lllll} & & \begin{array}{c}\text { Higher alcohols } \\ \text { per hectolitre of } \\ \text { abs. alcohol }\end{array} \\ \text { Bois Brandy, I817 (Lusson) ... } & \ldots & \ldots & 612 \\ \text { Saintonge, Cazes, 1896 (Lusson) } & \ldots & \ldots & 372 \\ \text { Gemozac, or de Fesson, I893 (Lusson) } & \ldots & 345 \\ \text { Clunis, 1875 (Lusson) } & \ldots & \ldots & \ldots & 345 \\ \text { Cognac, I873 (Rocques) } & \ldots & \ldots & \ldots & 304\end{array}$

From the hygienic point of view the ethers, furfurol, and especially the aldehydes, are undoubtedly of much greater importance than the higher alcohols, since admittedly the action of these substances on the organism is far more deleterious than that of the higher alcohols. From this point of view the attention of hygienists should be directed to the Marc brandies, which, as already stated, frequently contain consider. able quantities of aldehydes.

Interesting and, no doubt, valuable as the report is, it is hardly calculated to facilitate the work of the unfortunate public analysts who may be called upon to express an opinion as to the genuineness of a sample of brandy. The question, What is brandy? analytically speaking, still awaits solution. 